\title{
Peter Seland (1941-2013)
}

The neurology and neurosurgery community in Canada lost a good friend and one of its strongest supporters when Dr. Peter Seland died in Kelowna, BC on March 29, 2013 after a short illness with an aggressive form of lymphoma.

Peter was born and raised in Drumheller, Alberta, the dinosaur capital of Canada. He remained close to his small town roots. For many years neurologists visiting Calgary were often treated to a visit to Drumheller to meet Peter's parents Trygve and Norma and to wander around the badlands searching for dinosaur fossils.

After graduating from medical school at the University of Alberta in Edmonton in 1964 and completing a rotating internship, Peter served for three years as a Surgeon-Lieutenant in the Royal Canadian Navy based at Esquimalt and Comox, BC. In 1968 he returned to Edmonton for residency training in internal medicine and neurology (under the supervision of Dr. George Monckton) and obtained his FRCP in neurology in 1972. Soon after this he moved to Calgary to join the staff at the Calgary General Hospital and establish a practice as a consulting neurologist with his colleague from Edmonton, Dr. Roger West.

The Calgary General was the old established hospital in Calgary. Foothills Hospital had just opened in 1966 and the new medical school was about to graduate its first class in June 1973. As was the case in many academic centers at that time there was a distinct "town - gown" division. Foothills Hospital and the medical school were regarded with some degree of suspicion by many of the staff at the Calgary General. But right from the beginning Peter Seland was a strong supporter of the academic programs at Foothills Hospital and the University. He recognized that close cooperation between neurology and neurosurgery and related disciplines - and between different hospitals - was essential to provide the best patient care and to develop high quality teaching and research programs. He was one of the key players in the discussions which eventually led to the establishment in 1981 of a new Department of Clinical Neurosciences in Calgary at both the university and the hospital levels.

Peter had a major impact on neurology across Canada. From 1981 to 1988 he was a member of the council of the Canadian Neurological Society and served as president from $1986-1988$. He was also actively involved with the Royal College of Physicians and Surgeons of Canada as a member of the neurology specialty committee and chairman of the examination board for neurology. He always considered himself to be a general neurologist but his subspecialty interest was multiple sclerosis where he played a leading role locally and nationally. He established one of the first interdisciplinary multiple sclerosis clinics in Canada at the Calgary General Hospital and served as chairman of the medical advisory board of the MS Society of Canada from 1992 - 1999.

In 1992 Peter relocated to Kelowna, BC where he continued to work as a community - based consulting neurologist and served as chairman of the Department of Medicine at the Kelowna General Hospital. He also established another new multiple sclerosis clinic to serve patients from the southern interior of British Columbia.

No matter how busy he was Peter was always prepared to take on a new job or administrative responsibility. While he was still in Calgary he had been actively involved with the College of Physicians and Surgeons of Alberta and served a two year term as president of the College. Over the years he became increasingly interested in medical ethics, and in 1999 started a new career as Deputy Registrar (Ethics) for the British Columbia College of Physicians and Surgeons, a position which he held until his (partial) retirement in 2006.

Peter will be remembered by numerous residents and medical students as a highly respected teacher and mentor with exceptional clinical judgment. His friends and colleagues will never forget his infectious laughter and good humour, his love of a good party, his generosity (he always insisted on picking up the bill for drinks or dinner), and his skills as a home chef. We will all miss him and express our condolences to his wife Michele and his family. 